\title{
Complicated Case for Tavi-off-Label Indication
}

\section{Diana T}

Clinic of Cardiosurgery, University Hospital, St. Ekaterina, Sofia, Bulgaria

\begin{abstract}
This report describes the case of a 76-year-old female with reconstruction of the ascending aorta without aortic valve replacement in 2003 due to Type-Aaortic dissection. One year later she was diagnosed withsevere aortic regurgitation up to III degree. The last 3-4 years, the patient developed heart failure with dyspnea and frequent admissions for congestive heart failure.

After thorough multidisciplinary assessment between cardiologists and thoracic surgeons, TAVI was offered to the patient, who consented and accepted the risks of this intervention. The TAVI procedure was performed under general anesthesia. The left subclavian artery was chosen to introduce the valve prosthesis. Immediately after adjusting the prosthesisposition under fluoroscopyandreleaseditfrom the introduction system,the prosthesis dislocated in left ventriclewith huge aortic insufficiency. After unsuccessful attempts to reposition by pulling with a snare, a second valve -" valve in valve"was implanted. The patient was dischargedon the $7^{\text {th }}$ day after procedure in stable clinical condition.
\end{abstract}

Conclusion: TAVI has to be considered as an alternative treatment option to conservative treatment in selective cases with aortic regurgitation, if the patients are inoperable and have a poor prognosis.

Keywords: Transcatheter Aortic Valve Implantation (TAVI); Aortic Stenosis (AS); Aortic Regurgitation (AR)

\section{Introduction}

Surgical Aortic Valve Replacement (AVR) is the conventional treatment for severe aortic stenosis (AS). However, a high operative mortality of $7 \%$ to $10 \%$ is well recognized in high-risk groups $[1,2]$. Risk of AVR is increased by a number of factors, including increasing age and comorbidities, such as heart failure, respiratory and renal disease, prior cardiac surgery, and need for concomitant coronary revascularization.

Currently, there are 2 CE (European Conformity) marked devices with some similar fundamental design features: the selfexpanding CoreValve ReValving system (Medtronic Inc; Minneapolis, $\mathrm{MN}$ ) and the balloon-expandable Edwards SAPIEN prosthesis (EdwardLifesciencesInc; Irvine, CA), which is now available as the new generation, smaller profile, balloon-expandable Edwards SAPIEN XT prosthesisMultiple trials have assessed the efficacy of TAVI in terms of procedural success, early mortality, and short-term clinical outcomes [3-7]. Selection criteria have a crucial influence on complication rates and clinical outcomes after TAVI and are focused on the selection of the most appropriate patient group, prosthesis type and size, and delivery route [8]. As accepted techniques, experience, and skill of the operators have improved, the indications and criteria for patient selection have become broader.

Transcatheter aortic valve implantation (TAVI) has proven to be a safe, efficient new treatment option for inoperable patients with severe symptomatic aortic stenosis (AS). The current recommended treatment criteria for the two prosthetic systems do not include patients with aortic regurgitation (AR) [8]. This article presents the case of a valve-invalve procedure in which a CoreValve prosthesis was inserted through the leftsubclavian artery into a patient with severe AR.

\section{Case Report}

The patient was a 76-year-old femalewho in 2003, had undergone urgent cardiac surgery due to Type-A aortic dissection with reconstruction of the ascending aorta without aortic valve replacement.
One year later severe aortic regurgitation up to III degreewas diagnosed. The last 3-4 years, the patient developed heart failure with dyspnea (New York Heart Association functional Class III) with frequent admissions for congestive heart failure, but no angina. In December 2012 she had an episode of an acute heartfailure withpulmonary edema and continuous mechanical ventilation.

\section{Comorbidities}

The patient had history of Arterial Hypertension for more than 20 years reaching values of 200/100 $\mathrm{mm} \mathrm{Hg}$, usually $150 / 90 \mathrm{~mm} \mathrm{Hg}$; Bronchial asthma, Pulmonary fibrosis, Chronic renal failure, Impaired glucose tolerance and Thyroidpathology.

On clinical examination in admission the patient had signs of pulmonary congestion, auscultation for severe aortic regurgitation and moderate mitral regurgitation. The electrocardiogram (ECG) revealed atrial fibrillation,left axis deviation. Laboratory results were normal -Hb - 128 g/l; leuc -6.8/mmc; RBC.- 4.7/mmc, Hct - 0.41; PLT 303000/ $\mathrm{mmc}$; Creat- $110 \mathrm{mmol} / \mathrm{l}$; UREA $10.0 \mathrm{mmol} / \mathrm{l}$. Pulmonary function report showed moderate respiratory obstruction and low- vital capacity - FVC 66.2\%; FEV1 - 51.1\%; FEV1/FVC - 6.9\%. Transthoracic and Trans-esophageal echocardiography showed severe AR (Figure 1) confirmed by aortography, but no AS was present. The left ventricle was moderately dilated with an inner end diastolic diameter of $58 \mathrm{~mm}$ and an ejection fraction of $51 \%$, annulus - $22 \mathrm{~mm}$, parasternal long axis view aorta ascendens $-42 \mathrm{~mm}$, sinus width $-40 \mathrm{~mm}$, annulus $-22 \mathrm{~mm}$, mitral valve - MR - II degree.

*Corresponding author: Diana Trendafilova, Clinic of Cardiosurgery, University Hospital St. Ekaterina, Sofia, Bulgaria, Tel: +359 888275738; E-mail: dianalaztr@yahoo.com

Received June 24, 2014; Accepted October 29, 2014; Published October 31, 2014

Citation: Trendafilova D, Jorgova J, Petkov D, Nachev G (2014) Complicated Case for Tavi-off-Label Indication. J Vasc Med Surg 2: 162 doi: 10.4172/2329 6925.1000162

Copyright: ( 92014 Trendafilova D, et al. This is an open-access article distributed under the terms of the Creative Commons Attribution License, which permits unrestricted use, distribution, and reproduction in any medium, provided the original author and source are credited. 
Citation: Trendafilova D, Jorgova J, Petkov D, Nachev G (2014) Complicated Case for Tavi-off-Label Indication. J Vasc Med Surg 2: 162. doi: 10.4172/2329-6925.1000162

Page 2 of 3

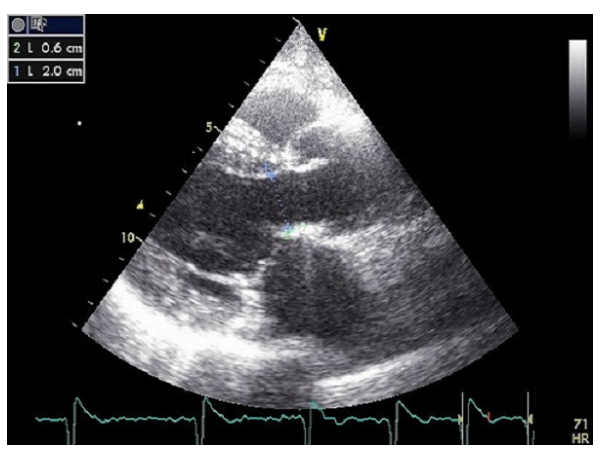

Figure 1: Transthoracic echocardiography (TTE).

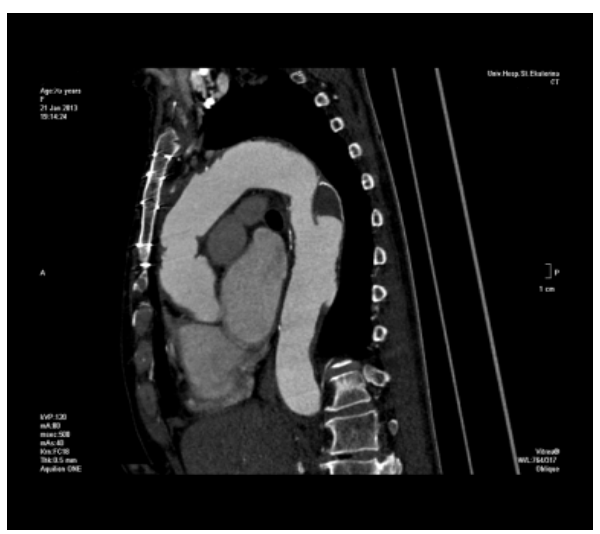

Figure 2: CT of the aorta.

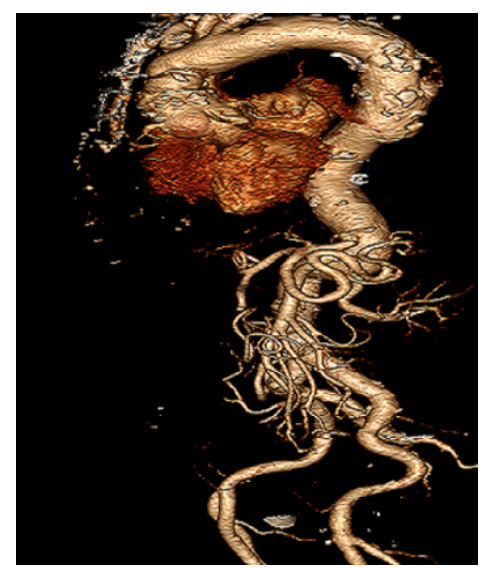

Figure 3: Aortic CT reconstruction.

Furthermore, coronary angiography was performed, which demonstrated no significant stenoses.Aortography and ECG-gated Computer Tomography (CT) with contrast of aorta and aortic valve revealed persistant partial dissection in ascending aorta, descending aorta - up to $36 \mathrm{~mm}$ with irregularities and ulcerations, local aortic dilatation up to $45 \mathrm{~mm}$ - localized dissection/plaque ulceration. Abdominal aorta and iliac arteries - elongated with tortuosity without dissection. Size of the left and right femoral arteries were $11 / 9.8 \mathrm{~mm}$ respectively, size of the left subclavian artery was $9-9.5 \mathrm{~mm}$ (Figures 2 and 3). Possible treatment options were:
1. Conservative medical treatment with unfavorable prognosis frequent hospitalizations against optimal medical therapy, episode of pulmonary edema.

2. Surgical valve prosthesis -AVR, MVR - previous thoracotomy, volume surgery in describing aortic pathology, comorbidities.

Her logistic European System for Cardiac Operative Risk Evaluation (EuroSCOREII ) was $46.38 \%$, STS Score was $11.7 \%$. The patient refused re-operation. After thorough multidisciplinary evaluation between cardiologists and thoracic surgeons, TAVI was offered as treatment option to the patient, who consented and accepted the risks of this intervention.

\section{Procedure}

The TAVI procedure was performed under general anesthesia. The left subclavian artery was chosen and an $18 \mathrm{Fr}(6 \mathrm{~mm})$ sheath was used to introduce the valve prosthesis. Femoral access was used as well to measure pressure invasivelyand HF pacing. The valve used in this case was a third-generation, large-sized Core Valve nitinolporcine prosthesis, which in full expansion is $29 \mathrm{~mm}$ in diameter, corresponding to aortic annulus diameters. Immediately after adjusting the prosthesis position under fluoroscopy and released it from the introduction system,the prosthesis disslocatedin the LV with huge aortic insufficiency.

After unsuccessful attempts to reposition by pulling with a snare we decided to implanta second valve - valve in valve - to stabilize the aortic annulus while pulling on the first with the snare (Figure 4). The second valve was implanted successfully (Figure 5) and the subclavian artery

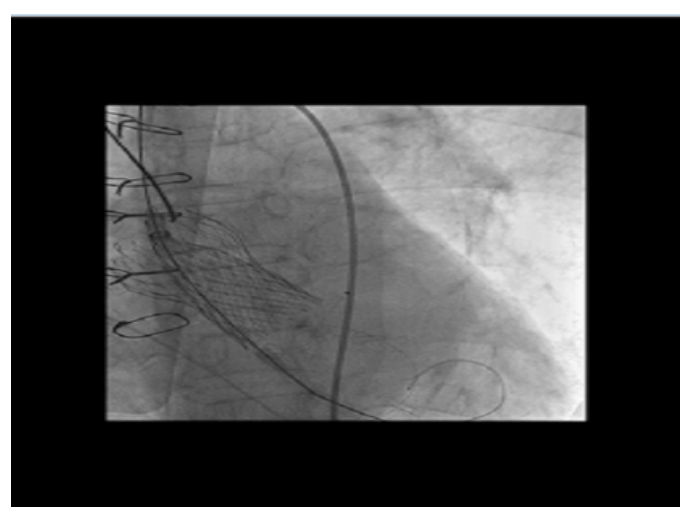

Figure 4: Valve in valve implantation.

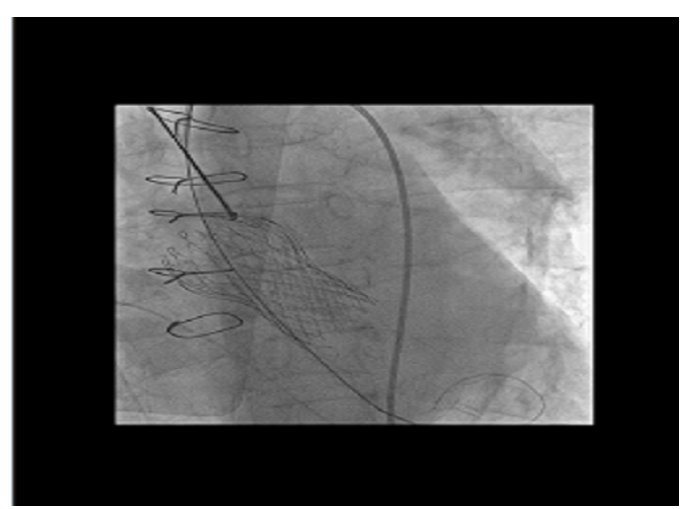

Figure 5: Valve in valve implantation. 
Citation: Trendafilova D, Jorgova J, Petkov D, Nachev G (2014) Complicated Case for Tavi-off-Label Indication. J Vasc Med Surg 2: 162. doi: 10.4172/2329-6925.1000162

Page 3 of 3

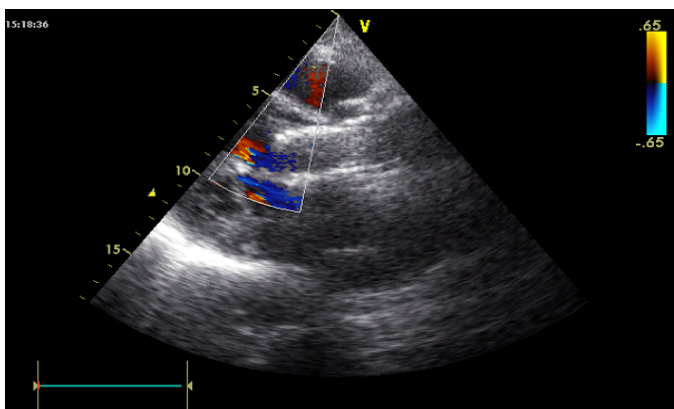

Figure 6: TTE - at 6 months of follow-up.

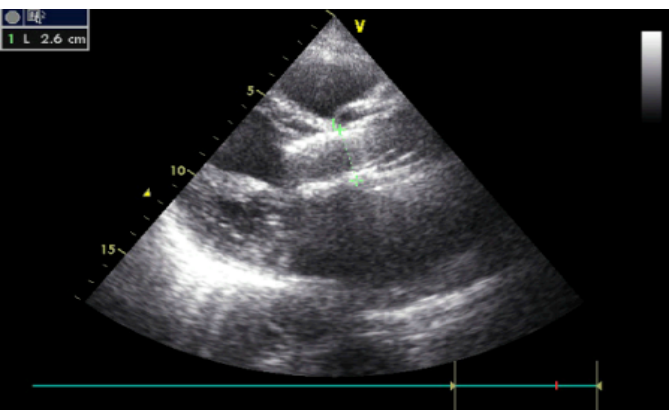

Figure 7: TTE- at 6 months of follow-up

access was surgically closed.Angiography showed aortic regurgitation - I-II degree, arterial pressure was 140/80 mm Hg. The patient was extubated 2 hours later in stable hemodynamic parameters. Clinilcal and echocardiographyc follow-up for the next days revealed low-grade aortic insufficiency, reduction of mitral regurgitation up to I degree and stable clinical condition. The patient was discharged on the $7^{\text {th }}$ day after procedure on the medical therapy - Clopidogrel, Aspirin, Sintrom for three months, ACE inhibitor, diuretic, digitalis.

Folow-up at 6 months showed good LVEF - 55\%, good prosthesis function with AoR - I degree, MR up to I degree and no signs of heart failure (Figures 6 and 7). 10 months after the procedure the patient was admitted in other hospital with pulmonary infection and acute respiratory failure. The patient diedwith signs of respiratory disstress syndrome.

\section{Discussion}

The existing indication for applying TAVI is inoperable, severe AS, and the results are promising [2,9]. Along with forthcoming results from long-term studies on the treatment of patients with inoperable AS and randomized studies comparing surgical Aortic Valve Replacement (AVR) and TAVI, the indications for TAVI are expected to be expanded to include operable high-risk patients with AS. This case of high surgical risk patient presents two intriguing and challenging aspects. Firstly, the indication was AR; and second the vascular access was limited to the left subclavian artery due to previous aortic reconstruction and residual pathology of the aorta.

It is clear, that the suggested case had contraindicationsfor both types of trans-catheter valves, considering aortic valve pathology. There are a few publications for off - label implantation of TAVIin such pathology. We chose Core-Valve prosthesis based on more appropriate as a configuration, self-expandable, with a wider proximal ring, gradually opening with the possibility of repositioning, an opportunity to further strengthen the ascending aorta in this case. In this case, the insertion of the CoreValve prosthesis resulted in instantaneous hemodynamic improvement and a marked relief in symptoms. AR was decreased from severe regurgitation to a trivial paravalvular leak, and the dimensions of the left ventricle normalized during the first six months following valve insertion. Patient'sleft ventricular ejection fraction increased from $51 \%$ to $55 \%$.

\section{Conclusion}

Advanced aortic pathology with severe aortic regurgitation remains a therapeutic problem in everyday clinical practice. New less invasive methods as TAVI could be considered as a treatment option in selective patients, who have a poor prognosis.

\section{References}

1. Asimakopoulos G, Edwards MB, Taylor KM (1997) Aortic valve replacement in patients 80 years of age and older: survival and cause of death based on 1100 cases: collective results from the UK Heart Valve Registry. Circulation 96: 3403-3408.

2. Edwards MB, Taylor KM (2003) Outcomes in nonagenarians after heart valve replacement operation. Ann Thorac Surg 75: 830-834.

3. Grube E, Schuler G, Buellesfeld L, Gerckens U, Linke A, et al. (2007) Percutaneous aortic valve replacement for severe aortic stenosis in highrisk patients using the second- and current third-generation self-expanding CoreValve prosthesis: device success and 30-day clinical outcome. J Am Coll Cardiol 50: 69- 76

4. Piazza N, Grube E, Gerckens U, den Heijer P, Linke A, et al. (2008) Procedura and 30-day outcomes following transcatheter aortic valve implantation using the third generation (18 Fr) Core Valve Re-Valving system: results from the multicentre, expanded evaluation registry 1-year following CE mark approval. Euro Intervention. 4: 242-249.

5. Webb JG, Altwegg L, Boone RH, Cheung A, Ye J, et al. (2009) Transcatheter aortic valve implantation: impact on clinical and valve-related outcomes. Circulation 119: 3009-3016.

6. Thomas M, Schymik G, Walther T, Himbert D, Lefèvre T, et al. (2010) Thirtyday results of the SAPIEN aortic Bioprosthesis European Outcome (SOURCE) Registry: A European registry of transcatheter aortic valve implantation using the Edwards SAPIEN valve. Circulation 122: 62-69.

7. Buellesfeld L, Wenaweser P, Gerckens U, Mueller R, Sauren B, et al. (2010) Transcatheter aortic valve implantation: predictors of procedural success--the Siegburg-Bern experience. Eur Heart J 31: 984-991.

8. Vahanian A, Alfieri O, Al-Attar N, Antunes M, Bax J, et al. (2008) Transcatheter valve implantation for patients with aortic stenosis: a position statement from the European Association of Cardio-Thoracic Surgery (EACTS) and the European Society of Cardiology (ESC), in collaboration with the European Association of Percutaneous Cardiovascular Interventions (EAPCI). Eur Heart J. 29: 1463- 1470 .

9. Nowicki ER, Birkmeyer NJ, Weintraub RW, Leavitt BJ, Sanders JH, et al. (2004) Multivariable prediction of in-hospital mortality associated with aortic and mitra valve surgery in Northern New England. Ann Thorac Surg 77: 1966-1977. 